\title{
Decision-making strategies in supply chain management with a waste-averse and stockout-averse manufacturer
}

\author{
Jian, M. ${ }^{a}$, Wang, Y.L. ${ }^{a}{ }^{, *}$ \\ ${ }^{a}$ School of Transportation and Logistics, Southwest Jiaotong University, Chengdu, P.R. China
}

\begin{abstract}
A B S T R A C T
Behavioral preferences is an important factor that affects the decision-making strategies of enterprises. Usually, the behavioral preferences will lead to decision-making that deviates from profit maximization. In this study, we investigate the influence of a dominant manufacturer's behavioral preferences on decision-making and subsequent impact on profits. This study looks at the profits of the manufacturer, retailer and the system as a whole. We construct a two-stage supply chain involving a retailer and a manufacturer who may have risk-neutral $(R N)$, stockout-aversion $(S A)$, waste-aversion $(W A)$, and stockout- and waste-aversion $(S W)$ preferences. Through a comparison and analysis of the four cases, we find that the manufacturer's wholesale price increases (decreases) with the $S A(W A)$ coefficient, while the retailer's order quantity is completely the opposite. The manufacturer's wholesale price is the highest in the $W A$ model, followed by the $R N, S A$ and $S W$ models, in that order. The retailer's order quantity is the largest and smallest in the $S A$ and $W A$ models, respectively, while the size of the order quantity between the $R N$ and $S W$ models depends on the ratio $m$ (the ratio of the $S A$ to the $W A$ ). Moreover, we also explore the changing trends of the decision-making and profits of the participants and the system profit with the degree of $S A$ and $W A$, comparing the profits of the four cases.
\end{abstract}

\section{ARTICLE INFO}

Keywords:

Decision-making strategy;

Supply chain management;

Waste-averse preferences;

Stockout-averse preferences

*Corresponding author:

wangyonglong@my.swjtu.edu.cn

(Wang, Y.L.)

Article history:

Received 6 July 2018

Revised 20 August 2018

Accepted 22 August 2018

(c) 2018 CPE, University of Maribor. All rights reserved.

\section{References}

[1] Schweitzer, M.E., Cachon, G.P. (2000). Decision bias in the newsvendor problem with a known demand distribtion: Experimental evidence, Management Science, Vol. 46, No. 3, 404-420, doi: 10.1287/mnsc.46.3.404. $\underline{12070 .}$

[2] Jian, M., Fang, X., Jin, L.-Q., Rajapov, A. (2015). The impact of lead time compression on demand forecasting risk and production cost: A newsvendor model, Transportation Research Part E: Logistics and Transportation Review, Vol. 84, 61-72, doi: 10.1016/j.tre.2015.10.006.

[3] Zhu, X.D., Li, B.Y., Wang, Z. (2017). A study on the manufacturing decision-making and optimization of hybridchannel supply chain for original equipment manufacturer, Advances in Production Engineering \& Management, Vol. 12, No. 2, 185-195, doi: 10.14743/apem2017.2.250.

[4] Niu, B., Chen, L., Zhang, J. (2017). Sustainability analysis of supply chains with fashion products under alterntive power structures and loss-averse supplier, Sustainability, Vol. 9, No. 6, 1-19, doi: 10.3390/su9060995.

[5] Choi, S. (2018). A loss-averse newsvendor with cap-and-trade carbon emissions regulation, Sustainability, Vol. 10, No. 7, 1-12, doi: $10.3390 /$ su10072126.

[6] Li, X., Li, Y. (2016). On the loss-averse dual-sourcing problem under supply disruption, Computers \& Operations Research, Vol. 100, 301-313, doi: 10.1016/j.cor.2016.12.011.

[7] Xu, X., Wang, H., Dang, C., Ji, P. (2017). The loss-averse newsvendor model with backordering, International Journal of Production Economics, Vol. 188, 1-10, doi: 10.1016/i.ijpe.2017.03.005.

[8] Yang, D., Xiao, T. (2017). Coordination of a supply chain with loss-averse consumers in service quality, International Journal of Production Research, Vol. 55, No. 12, 3411-3430, doi: 10.1080/00207543.2016.1241444. 
[9] Giri, B.C. (2011). Managing inventory with two suppliers under yield uncertainty and risk aversion, International Journal of Production Economics, Vol. 133, No. 1, 80-85, doi: 10.1016/i.ijpe.2010.09.015.

[10] Zhu, L., Ren, X., Lee, C., Zhang, Y. (2017). Coordination contracts in a dual-channel supply chain with a risk-averse retailer, Sustainability, Vol. 9, No. 11,1-21, doi: 10.3390/su9112148.

[11] Wu, M., Zhu, S.X., Teunter, R.H. (2013). The risk-averse newsvendor problem with random capacity, European Journal of Operational Research, Vol. 231, No. 2, 328-336, doi: 10.1016/j.ejor.2013.05.044.

[12] Oh, S., Rhodes, J., Strong, R. (2016). Impact of cost uncertainty on pricing decisions under risk aversion, European Journal of Operational Research, Vol. 253, No. 1, 144-153, doi: 10.1016/j.ejor.2016.02.034.

[13] Egging, R., Pichler, A., Kalvø, Ø.I., Walle-Hansen, T.M. (2017). Risk aversion in imperfect natural gas markets, European Journal of Operational Research, Vol. 259, No. 1, 367-383, doi: 10.1016/i.ejor.2016.10.020.

[14] Xiao, T., Choi, T.M., Yang, D., Cheng, T.C.E. (2012). Service commitment strategy and pricing decisions in retail supply chains with risk-averse players, Service Science, Vol. 4, No. 3, 236-252, doi: 10.1287/serv.1120.0021.

[15] Zhou, Y.-W., Li, J., Zhong, Y. (2018). Cooperative advertising and ordering policies in a two-echelon supply chain with risk-averse agents, Omega, Vol. 75, 97-117, doi: 10.1016/j.omega.2017.02.005.

[16] Zheng, W., Li, B., Song, D.-P. (2017). Effects of risk-aversion on competing shipping lines' pricing strategies with uncertain demands, Transportation Research Part B: Methodological, Vol. 104, 337-356, doi: 10.1016/i.trb.2017. $\underline{08.004}$.

[17] Liu, M., Cao, E., Salifou, C.K. (2016). Pricing strategies of a dual-channel supply chain with risk aversion, Transportation Research Part E: Logistics and Transportation Review, Vol. 90, 108-120, doi: 10.1016/j.tre.2015.11.007.

[18] Downward, A., Young, D., Zakeri, G. (2016). Electricity retail contracting under risk-aversion, European Journal of Operational Research, Vol. 251, No. 3, 846-859, doi: 10.1016/j.ejor.2015.11.040.

[19] Ohmura, S., Matsuo, H. (2016). The effect of risk aversion on distribution channel contracts: Implications for return policies, International Journal of Production Economics, Vol. 176, 29-40, doi: 10.1016/j.ijpe.2016.02.019.

[20] Li, B., Chen, P., Li, Q., Wang, W. (2014). Dual-channel supply chain pricing decisions with a risk-averse retailer, International Journal of Production Research, Vol. 52, No. 23, 7132-7147, doi: 10.1080/00207543.2014.939235. 


\section{APEM}

Advances in Production Engineering \& Management Letnik 13 | Številka 3 | September 2018 | Strani 345-357 https://doi.org/10.14743/apem2018.3.295
ISSN 1854-6250

Spletna stran: apem-journal.org Izvirni znanstveni članek

\title{
Strategije sprejemanja odločitev pri upravljanju dobavne verige s proizvajalcem, ki je nenaklonjen odpadkom in pomanjkanju zalog
}

\author{
Jian, M. ${ }^{a}$, Wang, Y.L. ${ }^{a}{ }^{*}$

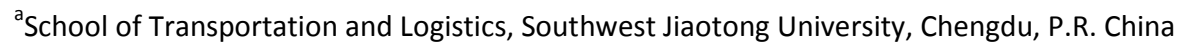

\begin{abstract}
POVZETEK
Vedenjski vzorci so pomemben dejavnik, ki vpliva na strategije odločanja podjetij. Običajno vedenjski vzorci vodijo v odločitve, ki ne zagotavljajo največjega dobička. $V$ študiji je proučen vpliv dominantnih proizvajalčevih vedenjskih vzorcev na odločanje in posledični vpliv na dobiček. Študija obravnava dobiček proizvajalca, trgovca na drobno in sistema kot celote. Zasnovana je dvostopenjska oskrbovalna veriga, ki vključuje trgovca na drobno in proizvajalca, ki lahko ima nevtralno tveganje ( $R N)$, nenaklonjenost pomanjkanju zalog $(S A)$, nenaklonjenost odpadkom (WA) ali nenaklonjenost pomanjkanju zalog in odpadkom $(S W)$. S primerjavo in analizo vseh štirih primerov je ugotovljeno, da se proizvajalčeva veleprodajna cena poveča (zmanjša) s koeficientom $S A(W A)$, količina naročila prodajalca na drobno pa se giblje v nasprotni smeri. Proizvajalčeva veleprodajna cena je najvišja v modelu $W A$, sledijo modeli $R N$, $S A$ in $S W$. Količina naročila trgovca na drobno je največja in najmanjša v modelih $S A$ in $W A$, medtem ko je velikost naročila med modeli $R N$ in $S W$ odvisna od razmerja $m$ (razmerja med $S A$ in $W A$ ). Poleg tega so raziskani tudi spreminjajoči se trendi odločanja ter dobička udeležencev in dobička sistema s stopnjo $S A$ in $W A$, pri čemer je primerjan dobiček štirih primerov.
\end{abstract}

\section{PODATKI O ČLANKU}

Ključne besede:

Strategija sprejemanja odločitev;

Upravljanje z dobavno verigo;

Nenaklonjenost odpadkom;

Nenaklonjenost pomanjkanju zalog

*Kontaktna oseba:

wangyonglong@my.swjtu.edu.cn

(Wang, Y.L.)

Zgodovina članka:

Prejet 6. julija 2018

Popravljen 20. avgusta 2018

Sprejet 22. avgusta 2018 